in Iran are indexed in international databases, the output of Iranian researchers in branches of medicine related to mental health is less than may appear to be the case.

\section{Mental health promotion and policies}

The N ational Programme of M ental Health, which seeks to integrate mental healthcare within primary healthcare, was started in 1989 as a pilot study in two rural areas (Yasamy \& Bagheri Yazdi, 2004). In 1995 it was jointly evaluated by the World $\mathrm{H}$ ealth $\mathrm{O}$ rganization and the Tehran Psychiatric Institute. The programme was recognised as one the most successful in the region (Murthy, 2002).

The aim is to establish a hierarchical, pyramid-like At the base of the pyramid there are health workers known as Behvarz, who are mainly local residents of each primary healthcare area; they are trained to recognise, refer and follow

\section{psychiatric cases \\ to the higher}

level, which

comprises rural health centres.

\section{Non-biological treatments are not extensively available, being mainly limited to four or five major cities in the country.}

referral system. At the base of the pyramid there are health workers known as Behvarz, who are mainly local residents of each primary healthcare area; they are trained to recognise, refer and follow psychiatric cases to the higher level, which comprises rural health centres (Fenton, 1998). C urrently, $21.7 \%$ of the urban population and $82.8 \%$ of the rural population is covered by the $\mathrm{N}$ ational Programme of Mental $\mathrm{H}$ ealth (Yasamy et al, 2001).

\section{Future of psychiatry in Iran (opportunities and threats)}

The advancement of psychiatric education and the promotion of mental health policies in the past decade have profoundly affected psychiatric services. At present, it seems that there are enough psychiatrists in major cities throughout the country, and most psychotropic medications are available in Iran. All psychiatric hospitals are equipped with modern ECT machines.

O $n$ the other hand, non-biological treatments are not extensively available, being mainly limited to four or five major cities in the country. Iran lacks a practical and comprehensive mental health act. Limited coverage of mental health expenses by insurance companies has affected psychiatric care in both the private and the governmental sectors. D espite a dramatic increase in recent years, the mental health budget still remains highly insufficient. The Mental Health Bureau of the Ministry of Health and the Iranian Psychiatric Association have been struggling to increase the budget.

\section{References}

Bash, K. W. \& Bash-Liechti, J. (1969) Studies on the epidemiology of neuropsychiatric disorders among the population of Shiraz, Iran. Social Psychiatry, 9, 163-171.

Fenton, W. S. (1998) In M ental Health in Our Future Cities (eds D. Goldberg \& G. Thornicroft). Maudsley Monograph 42. Philadelphia, PA: Psychology Press.

Hashemi Mohammad Abad, N. \& London, M. (2003) Psychiatric practice in Iran and the UK. Psychiatric Bulletin, 27, 190-191.

International $\mathrm{N}$ arcotics Control Strategy (2003) Report released by the Bureau for International $\mathrm{N}$ arcotics and Law Enforcement Affairs.

Iran Centre of Statistics (2003) Annual Report. Tehran: Iran Centre of Statistics.

Kermani, E. J. (1966) Psychiatry in Iran. American Journal of Psychiatry, 122, 949-952.

Ministry of Health and Medical Education (2003) Statistics on Psychiatric Beds in Iran. Tehran: Ministry of Health and Medical Education.

Motamedi, S. H., Yasami, M., Karbasi, H., et al (1998) Determination of the prevalence of mental illnesses in two rural areas of Kerman. Journal of the Kerman University of Medical Sciences, 5, 31-36.

Murthy, R. S. (2002) Mental health in the Islamic Republic of Iran. Andishe Va Raftar, 7 (suppl. 4), 40-57.

$\mathrm{N}$ ational Research Centre of Medical Sciences (2003) Statistics on Psychiatric Beds in Iran. Tehran: National Research Centre of Medical Sciences.

N oorbala, A., Bagheri Yazdi, S. A., Yasamy, M. T., et al (2004) Mental health survey of the adult population in Iran. British Journal of Psychiatry, 184, 70-73.

O midvari, S., Bina, M. \& Yassemi, M. T. (2001) Pre-hospitalization pathways among psychiatric patients in Imam Hussain Hospital in 1999. Andishe Va Raftar, 6, 4-12.

Sadeghi, M. (2003) Iran. In Handbook of Cultural Health Assessment (ed. C. D'Avanzo). St Louis, MO: C. V. Mosby.

Sartorius, N., Davidian, H., Emberg, G., et al (1983) Depressive Disorders in Different Cultures. Report on the WHO Collaborative Study on Standardized Assessment of Depressive Disorders. Geneva: World Health O rganization.

UNICEF (2003) At a Glance: Iran (Islamic Republic of) Statistics. N ew York: UN ICEF.

World Health O rganization (2003) The World Health Report, Country Profiles, Iran (Islamic Republic of). Geneva: WHO.

Yasamy, M. T. \& Bagheri Yazdi, S. A. (2004) National Programme of Mental Health. Tehran: Ministry of Health and Medical Education.

Yasamy, M. T., Shahmohammadi, D., Bagheri Yazdi, S. A., et al (2001) Mental health in the Islamic Republic of Iran: achievements and areas of need. Eastern Mediterranean Health Journal, 7, 381-389.

\title{
Mental health in Lithuania
}

\section{Dainius Puras}

Department of Psychiatry, Vilnius University, email: dainius.puras@mf.vu.It

ithuania is a country with an approximate area of $65000 \mathrm{~km}^{2}$. Its population is 3.422 million, and the gender ratio (expressed as men per 100 women) is 87 . The proportion of the population under the age of 15 years is $18 \%$, and the proportion above the age of 60 years is $20 \%$. The literacy rate is $99.6 \%$ for both men and women. The country is in the higher middle-income group (by World Bank 2004 criteria).

The health budget represents $6 \%$ of the country's gross domestic product. The per capita total expenditure on health is $\$ 478$ (international \$) and the 
per capita government expenditure on health is $\$ 337$. Life expectancy at birth is 66.2 years for males and 77.6 years for females. Healthy life expectancy at birth is 59 years for males and 68 years for females (World $H$ ealth O rganization, 2005).

\section{Cultural context}

Lithuania has undergone a marked transition in its economic, social and cultural life. After economic decline in the 1990s, the economy started to grow significantly after 2000. Similar trends can be observed in the dynamics of public health indicators: they reached their worst in 1994; after that a gradual improvement in the indicators of mortality and general morbidity was observed. However, high levels of social pathology remain (including vio lence, suicides, alcohol misuse and other self-destructive behaviours); this is combined with a stigmatising approach by the general population towards people with a mental disturbance and other vulnerable groups. Lithuania is among the countries with the highest rates of suicide in Europe, and indeed the world (42-44 per 100000 per year during the last 10 years), with middleaged rural males the group at highest risk (among whom the rates of suicide exceed 100 per 100000 ). According to a World Health O rganization (2002) report, youth homicide rates in Lithuania (5.4 cases per 100000 of the population aged 10-29 years) and other Baltic countries are several times higher than those in 'old' member states of the European U nion (EU) and Central European countries, but none the less are three times lower than those in Russia. Recently the problem of bullying in schools has been recognised as a serious issue (it appears that more than half of all schoolchildren in Lithuania are involved in bullying).

\section{Psychiatric services}

Analysis of existing data about financial and human resources invested in the mental healthcare system has raised questions for policy makers about the effectiveness of the traditional investments. Lithuania, like other countries of Eastern Europe, does not have a problem with a lack of psychiatrists and psychiatric services. The largest proportion of physical and human capital is concentrated in psychiatric institutions, with large numbers of beds, psychiatrists and increasing funding for reimbursement for the new generation of psychotropic medications. H owever, the other components of care are lacking, such as community-based housing, psychosocial and vocational rehabilitation, psychotherapy, community-based child mental health services, and supportive services for families at risk. The po litical will is needed to develop these as priorities and as alternatives to the pow erful system of residential institutions and psychiatric hospitals.

In 1997 a new network of municipal out-patient psychiatric services (municipal mental health centres) was launched; the total number of such centres throughout the country was 64 in 2004 . It was a very important first step in the development of communitybased services and mental health promotion. However, the composition of staff in the centres is too 'medicalised': the 617 staff members in 2002, for example, comprised $32 \%$ psychiatrists, $33 \%$ nursing staff, $22 \%$ social workers and $13 \%$ psychologists. The annual general cost of reimbursement of psychotropic medications prescribed by psychiatrists attached to these municipal mental health centres is two times higher than the sum of the running costs of all the mental health centres (including salaries for mental health teams and other staff).

The number of beds in psychiatric hospitals has steadily decreased, from 5380 in 1991 to 2996 in 2003. How ever, this has been achieved to a certain extent through the transfer of patients with a chronic mental illness from psychiatric hospitals (which are under the Ministry of $\mathrm{H}$ ealth and funded from obligatory health insurance funds) to psychiatric long-stay care institutions (which fall under the system of social welfare). In these centralised large residential institutions (of which there are over 20 throughout the country) the number of clients is more than 6000 . The new network of municipal mental health centres (mentioned above) is not currently able to start the process of deinstitutionalisation, and there are waiting lists for placement in residential institutions, in the absence of alternative community-based services.

Another gap which was identified during an analysis of resources and processes is a lack of sustainable and effective activities in the field of mental health promotion and the prevention of mental disorders. There are many new initiatives by municipal authorities and nongovernmental organisations (NGOs) in the field of mental health promotion and prevention; however, these lack a tradition of measuring their effectiveness and sustainability of funding. Also, general practitioners (GPs) are not involved in mental health issues, partly because it was planned that the municipal mental health centres would take care of all people who are in need of outpatient mental healthcare. $\mathrm{N}$ ow it is becoming obvious that G Ps need to be involved as gatekeepers in primary mental healthcare, as the municipal mental health centres are receiving too many referrals of common cases.

These findings may be useful for the develo pment of modern mental health policies in the countries of Eastern and Central Europe, which were deprived for decades of the possibility of introducing evidence-based mental health policies and services.

During an analysis of the performance of the national mental healthcare system, it became clear that existing policies and programmes do not include economic or so cial outcomes, which should be monitored as criteria by which to measure the effectiveness of resources and processes (services). However, there are some indicator targets which the Lithuanian Health Programme and the State Programme on Prevention of Mental $D$ isorders have been planning to reach, for example to reduce the suicide rate to 25 per 100000 and to reduce morbidity from alcoholic psychosis to 10 per
Lithuania is among the countries with the highest rates of suicide in Europe, and indeed the world ... with middle-aged rural males the group at highest risk

(among whom the rates of suicide exceed 100 per $100000)$.

Now it is

becoming obvious that GPs need to be involved as gatekeepers in primary mental healthcare, as the municipal mental health centres are receiving too many referrals of common cases. 
100000 by 2005 . It is obvious now that these goals have not been reached; neither has a primary goal of the State Programme on Prevention of M ental D isorders: 'to create an effective community-level network of social psychiatric structures by including N GO s in service provision'.

\section{Psychiatric training and education}

It is difficult to
compete for
national and
international
research funds
against fields like
cardiology,
oncology,

rheumatology and other traditional priorities in health research, which have separate state-funded research institutes from Soviet times.

An improvement
is required in the
governance of the
systems in order
to make mental
health systems
accountable and
effective and to
enable them to
meet the needs of
patients.

The system of training in psychiatry and other mental health and allied professions is undergoing changes to wards harmonisation with EU standards. After 6 years of undergraduate medical education and 1 year of general internship, graduates of medical schools (there are medical faculties at Vilnius U niversity and at Kaunas Medical U niversity) may choose 4 years' residency in two psychiatric specialties - general psychiatry and child and adolescent psychiatry. Courses of continuing medical education are also available in these medical schools. Training courses in psychotherapy are available for both medical doctors and psycho logists. So cial work is developing as a new specialty.

\section{Research}

Research in the field of psychiatry and mental health is not very well developed, mainly because of a lack of research capacity and the absence of research institutions in these fields. It is difficult to compete for national and international research funds against fields like cardiology, oncology, rheumatology and other traditional priorities in health research, which have separate state-funded research institutes from Soviet times. Most of the research in the field of psychiatry and mental health is carried out at Vilnius U niversity and Kaunas Medical U niversity, by PhD doctoral fellows and teaching faculty. Recently PhD theses have been defended on subjects such as eating disorders, autistic spectrum disorders, depression and suicide. In 2004 the first epidemiological study in Lithuania in the field of mental health was completed - the prevalence of child mental health problems was evaluated by a joint research team at Vilnius U niversity with the use of validated instruments. The first attempts at the evidence-based assessment of mental health systems have been provided by the research team in Vilnius U niversity. The problems of research capacity in the field of mental health and unsustained funding remain unsolved.

\section{The futue}

Completion of a 'country profile' (Puras et al, 2004) was a very important exercise in the country, which is looking forward to developing and implementing an evidence-based mental health policy and improving both the performance of the mental health system and indicators of population mental health. The country profile revealed a phenomenon common to most Eastern European countries, whereby statistical accounts keep the tradition of presenting processes as outcomes, while the modern assessment of outcomes of services, programmes and policies is lacking. This tradition of monitoring the amount of processes as if they were outcomes creates a vicio us circle in which a system of services that do not meet the modern requirements ofa public mental health approach and the needs of patients becomes a serious obstacle to the formulation, development and implementation of new mental health policies.

Analysis of the findings from the country profile identified the gaps in the existing mental healthcare system and raised the question of the need for a national evidence-based mental health policy. After a World $\mathrm{H}$ ealth $\mathrm{O}$ rganization ministerial conference on mental health, the Lithuanian M inister of $\mathrm{H}$ ealth appo inted the Committee for Mental $\mathrm{H}$ ealth, which has prepared a draft of a new mental health policy. This draft new mental health policy is currently being debated.

In conclusion, there is an obvious need to establish a modern culture of evaluation, independent assessment and research within the mental health sector in the countries of $C$ entral and Eastern Europe (Jenkins et al, 2001). These countries fall into two groups economically, with some (e.g. the Baltic states) seeing an impro ving economy but others experiencing greater economic difficulties. It is the case, however, that both groups have problems in the field of mental health. In this context there is a need for responsible, transparent and evidence-based decisions over the allocation of resources. An improvement is required in the governance of the systems in order to make mental health systems accountable and effective and to enable them to meet the needs of patients. Lithuania could be a good candidate as a demonstration country, with its improving economy and quality of life, in the development of modern mental health services as an alternative to the traditional system of centralised psychiatric institutions.

\section{References}

Jenkins, R., Tomov, T., Puras, D., et al (2001) Mental health reform in Eastern Europe. Eurohealth, 7, 15-21.

Puras, D., Germnanavicius, A., Povilaitis, R., et al (2004) Lithuania mental health country profile. International Review of Psychiatry, 16, 117-125.

World Health O rganization (2002) Violence and Health. Geneva: WHO

World Health O rganization (2005) Mental Health Atlas 2005. Geneva: WHO 